\title{
Can Creativity Be a Collective Virtue? Insights for the Ethics of Innovation
}

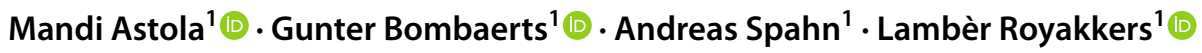

Received: 29 July 2020 / Accepted: 29 April 2021 / Published online: 14 May 2021

(c) The Author(s) 2021

\begin{abstract}
Virtue accounts of innovation ethics have recognized the virtue of creativity as an admirable trait in innovators. However, such accounts have not paid sufficient attention to the way creativity functions as a collective phenomenon. We propose a collective virtue account to supplement existing virtue accounts. We base our account on Kieran's definition of creativity as a virtue and distinguish three components in it: creative output, mastery and intrinsic motivation. We argue that all of these components can meaningfully be attributed to innovation groups. This means that we can also attribute the virtue of creativity to group agents involved in innovation. Recognizing creativity as a collective virtue in innovation is important because it allows for a more accurate evaluation of how successful innovation generally happens. The innovator who takes a collective virtue account of creativity seriously will give attention to the facilitation of an environment where the group can flourish collectively, rather than only nurturing the individual genius.
\end{abstract}

Keywords Collective creativity $\cdot$ Innovation $\cdot$ Creativity $\cdot$ Virtue $\cdot$ Collective virtue

\section{Introduction}

Pixar has quite exceptionally managed to maintain a high standard for the movies it releases. In 2021 the animation studio holds in 16 academy awards, 10 golden globes, and many more awards and nominations that it has been winning steadily since 1995 (Wikipedia, 2021). Leadership scholar Linda Hill, who studied the leadership at Pixar and other companies, notes that Pixar productions are products of a special kind of innovation process. At Pixar there is no leader with a vision who leads others to execute that vision. Instead, Pixar's working culture is conducive to something Hill calls "collective genius" (Hill, 2014). Every employee, regardless of rank, has the opportunity to give the director of

Mandi Astola

m.a.astola@tue.nl

Gunter Bombaerts

g.bombaerts@tue.nl

Andreas Spahn

a.spahn@tue.nl

Lambèr Royakkers

1.m.m.royakkers@tue.nl

1 Eindhoven University of Technology, De Zaale, Atlas 9.328, Eindhoven, The Netherlands a movie notes. The team is diverse and arguments and conflicts happen often and are even encouraged (Catmull, 2008; Hill, 2014). It is often said that the best ideas can come from unexpected sources. John Stuart and Harriett Taylor Mill famously argued that an idea becomes better when exposed to a rich multitude of perspectives. The best way to gain knowledge is also by "studying all modes in which it can be looked at by every character of mind" (Ch. 2, Mill, 1869). Additionally, recommendations for diverse teams, for productivity reasons, are often found in management literature (Bassett-Jones, 2005; Belbin, 2012; Paulus, 2003). Work in design studies suggests collective creativity plays, or can play, a role in many different areas of product and service innovation (Sanders \& Stappers, 2012). This type of literature shows that creative innovations do not always originate in the heads of individual geniuses. Often genius ideas are co-created and their origins can best be described as interpersonal. Hill even argues that visioneering is generally not an appropriate way to lead innovation. She favors Pixar's approach to facilitating collective genius (Hill, 2014).

Just like the conception of "genius," innovation is heavily associated with creativity (Sawyer, 2012). And creativity is seen by many philosophers as an inherently valuable character trait, or virtue (Kieran, 2018; Zagzebski, 1996). Recent work in ethics of innovation has therefore rightfully called 
for attention to the way innovation processes, rather than products, contribute to human flourishing. This work has, in particular, recognized the inherent value of creativity as a virtue (Sand, 2018; Steen, 2013). Virtue theories see inherently valuable character traits, or virtues, as fundamental units of moral good. The good life consists of the development and practice of the virtues (Aristotle, Nichomachean Ethics; Zagzebski, 1996). Approaches to innovation ethics, like value sensitive design and technology assessment, often equate ethical innovation with the products of innovation and their societal consequences. However, if innovation processes are bound up with creativity, then the processes of innovating may contribute to human flourishing just like the products of innovation do.

However, none of this work has considered creativity as a collective phenomenon. We supplement the existing work on the virtue of creativity in innovation by exploring whether creativity can be a collective virtue in organizations that engage in product and service innovation. The purpose of this article is to lay down a possible groundwork for a collectivist account of creativity as a virtue, in response to the interest that other fields have taken to this phenomenon. Recognizing this collective virtue, we argue, is a valuable addition to existing accounts of creativity as a virtue in innovation. Recognizing creativity as a collective virtue will make virtue accounts more accurate about how much successful innovation happens. If one takes our argument seriously, then one will recognize the moral value of facilitating collective creativity within innovation practices, in addition to nurturing the individual creative genius.

Our argument proceeds as follows: first, we outline a definition of creativity as a virtue. Since the most complete account of creativity as a virtue has been constructed in the context of aesthetics and philosophy of art, we will use such an account, namely, that of Matthew Kieran. Second, since Kieran's definition of creativity as a virtue is contextdependent, we construct an account of what it means to have the virtue of creativity in the context of product and service innovation. Thirdly, we explore whether it is possible for that conception of creativity to apply to an innovation group. We ground this argument in work on collective virtues, and in our conception of what creativity means in the context of innovation.

We conclude that creativity in the context of innovation can be a group virtue. We are not claiming that the virtue of creativity cannot be possessed by individuals, but that it can also be possessed by collectives. The collective creativity described in management literature can in fact be seen as an inherently valuable group trait.

Philosophy of innovation will benefit from devoting more attention to group traits like creativity driving innovation. For one, this will make innovation ethics more accurate regarding how innovation actually happens. Secondly, there is a normative argument to be made for recognizing collective creativity. Often only the leaders of successful projects are acknowledged for collective efforts, when the creative outcomes are not necessary products of their creativity only. There is a sense in which this is an unfair practice of creditgiving. It could be argued that the idolization of individuals, leaders, or visionaries also leads to an individualistic and competitive culture which has a well-known set of disadvantages. Again, we do not claim that innovation ethics should focus only on collective creativity, and that individual creativity is irrelevant. We think that the collective virtue perspective it is an often-overlooked one that deserves more attention.

\section{When Does One Possess the Virtue of Creativity?}

To begin, it must be established what is meant by creativity as a virtue. What we make of creativity partially depends on the kind of virtue theory we endorse. We base our account on a framework where the virtues are seen as "character virtues" rather than strictly either moral or epistemic. ${ }^{1}$ Within such an account, the virtue of creativity would also be seen as an excellence of character with a relationship to all transcendentals, rather than focusing on how creativity relates to the true or the good in particular. If one sees creativity as a trait in service of either the good or the true, one may define it differently. For instance, a philosopher investigating creativity as an epistemic virtue may be more inclined to define it as a form of insightfulness (Carter, 2017). We consider creativity as a character trait with a relationship to the good, the true and the beautiful.

The most complete account of creativity as a charactervirtue, with a relationship to all trancendentals, is that of Matthew Kieran. He distinguishes creativity as a capacity which most people have, from creativity as a virtue, which only exceptionally creative people possess (Kieran, 2018). A person with the virtue of creativity, he writes "is someone who has acquired a certain degree of mastery and knows what she is doing in coming up with novel and worthwhile ideas or artifacts. In doing so, she is motivated by the values internal to the relevant domain and chooses what she does for reasons that hook up with those values in the right kind of ways".

We distinguish three components in Kieran's definition. We will refer to these three components as teleological, procedural and motivational. Each of these components is necessary but by itself insufficient for possessing the virtue

\footnotetext{
${ }^{1}$ MacIntyre and Anscombe also exemplify such a view of the virtues as we describe (Anscombe, 1958; Macintyre, 1986).
} 
of creativity. A virtuously creative person must possess them all. We will explain these briefly and how this dissection of components of virtue can be supported by other work in virtue ethics.

\section{Teleological}

The teleological part of Kieran's definition is the requirement: "coming up with novel and worthwhile artifacts." This refers to the successful reaching of the end-goal or telos of creativity. The telos of creativity is the ability to bring about novel and worthwhile artifacts. Kieran takes this component from Boden's definition of creativity, "the ability to come up with ideas or artifacts that are new, surprising, and valuable" (pp. 1, Boden, 2003).

Most virtue theories acknowledge a "teleological component" in the definition of virtue. Virtue theories are sometimes even categorized together with utilitarianism as teleological theories, as opposed to deontological theories (Macdonald \& Beck-Dudley, 1994). This is because virtue ethicists generally accept that cultivating all the virtues leads to a morally valuable goal, a flourishing life, or eudaimonia. ${ }^{2}$ Driver makes the goal of hitting the target the focus of an account of consequentialist virtues (Driver, 1989). However, for each virtue individually, there is also a certain goal. Zagzebski phrases this as the virtue "hitting its target" (Zagzebski, 1996). The target of benevolence, for instance, is helping another. She argues that we would not, and should not, praise someone as being benevolent if they meant well but kept acting in such a way that others are disadvantaged by them rather than helped. Such a person may have a virtuous motivation, but does not hit the target, and hence does not possess the virtue. ${ }^{3}$

If we follow Kieran's definition, the target of the virtue of creativity is "the ability to come up with ideas or artifacts that are new, surprising, and valuable" (Kieran, 2014). The meaning of "new, surprising, and valuable" requires some reflection. Kieran does not go into this and investigating exactly what this means would be a whole other article, hence, we make some assumptions. "New" we will take to mean that the artifact or idea did not exist before. "Surprising" we take to mean that there is something about the artifact or idea that makes people feel surprise. Some virtue ethicists see the emotion of admiration as a way of recognizing moral virtue (i.e. Zagzebski, 2017). Perhaps the emotion of surprise is a way of recognizing originality in an artifact or idea which hits the target of creativity. Kieran suggests

\footnotetext{
${ }^{2}$ Philosophers however disagree on whether virtues are grounded in the way they lead to eudaimonia, or whether eudaimonia is simply a common consequence of practicing the virtues.

${ }^{3}$ For more discussion on this, see Zagzebski (1996).
}

that the meaning of "valuable" or "worthwhile" should be determined in accordance with the nature of the activity one is undertaking. For the context of art, most would agree that to be valuable, an artwork should be beautiful or powerful. However, what is valuable as an artwork is not necessarily valuable as a scientific hypothesis. Hence, for each context, the meaning of "valuable" should be evaluated differently.

One may question whether creativity should be assessed in such a context-dependent way. After all, creative people often show creativity across a range of different contexts and activities. However, if we hold the view that virtuously creative people produce valuable outputs, then we must have some basis for what counts as valuable. This contextspecificity of what counts as valuable aligns with the kind of virtue theory that places emphasis on tradition and culture as determining the substance of the virtues, in the tradition of MacIntyre (MacIntyre, 1986).

\section{Procedural}

In addition to producing new, surprising and valuable artifacts or ideas, Kieran argues that creativity as a virtue also requires "a certain degree of mastery" and that the agent "knows what she is doing in coming up with novel and worthwhile ideas or artefacts." This, we see as the procedural component of Kieran's definition. As an illustration, Kieran discusses the hypothetical case of a stroke patient who tries to write but due to neural damage, ends up producing sequences of beautiful and artistic markings on paper. Although the person may be acting from a virtuous motivation, is exhibiting perseverance, and is producing something novel, we would not consider them creative in this action (Kieran, 2018). Hence Kieran requires that creative persons have the kind of control over their creations that would separate them from this hypothetical stroke patient.

Kieran outlines different types of control that creative people often have over their creations. Firstly, a creative person can be agential in fulfilling her intentions when creating. For instance, one expects that a painter making strokes on a canvas intended the strokes to look as they do, and that she or he would be able to paint different looking strokes if she or he decided to. Secondly, a creative person can make judgements about whether to keep or discard "happy accidents" or creations which were unintended (Kieran, 2018). A painter can accidentally splash paint on a painting and decide to keep the stain, because she or he decides that it contributes to the artwork. The point is that this kind of judgement requires mastery and relevant understanding. The painter uses his or her aesthetic understanding to decide whether the stain can become a part of the painting or not. 
The conception of mastery seems to imply authorship. There are various discussions in the philosophy of art and aesthetics about what exactly counts as authorship. ${ }^{4}$ These discussions reach far outside the scope of this paper. For our purposes here, we accept Kieran's suggestion that mastery requires a match between the artist's intentionality and the new, surprising and valuable output, in such a way that the artist ultimately "knows what they are doing."

\section{Motivational}

Most virtue theorists, including Kieran, recognize the need for a virtuous motivation as a part of any virtue. The motivational component, also needed for the virtue of creativity, is encompassed by the last part of Kieran's definition: "In doing so, she is motivated by the values internal to the relevant domain and chooses what she does for reasons that hook up with those values in the right kind of ways." A motivational component is necessary for the trait to be a virtue, Kieran states citing Aristotle (Kieran, 2018). For each virtue, there is a set of proper accompanying motivations. For instance, we would not praise a person as benevolent, if we knew for a fact that their benevolence was motivated by egoism, and the ambition to improve one's reputation. A benevolent person must be motivated by a motivation proper to the virtue of benevolence, like love, duty or empathy (Zagzebski, 2017).

Kieran argues that the right motivation for the virtue of creativity is intrinsic motivation for that particular creative activity. Think of the delight that poets or artists take in the process of creating their art and of expressing themselves through it. This is wholly different from someone making a painting only in order to make money from it, or other extrinsic motivations. Kieran defines intrinsic motivation as being driven by "the values internal to the relevant domain." Therefore, a creative artist can be intrinsically motivated by aesthetic usage of color and form, expression or any other value inherent to art. Kieran discusses the example of a creative hedge-fund owner. The virtue of creativity in hedgefund management seems paradoxical because the relevant values in hedge-fund owning and managing have to do with gaining money, a typical external reward. However, Kieran argues that a creative hedge-fund owner should not be motivated by earning money in the sense that he or she is just doing it to have money, but he or she must take pleasure in the practice of money-making itself. If one is motivated by an interest in hedge-funds and finance, or enjoys thinking outside the box when it comes to strategy, then this can be an intrinsically motivated hedge-fund owner (Kieran, 2018). Again, what intrinsic motivation means for a hedge-fund owner is substantially different from what it means for an artist. The "relevant values" are different in different creative contexts. The motivational component is therefore also context-dependent.

Kieran does not take a strong stance on the place of emotions in creative motivations. Other philosophers have however described the role of emotions in virtue in more detail. Zagzebski describes the virtuous motivation as "a persistent tendency to be moved by a motive of a certain kind" a motive being "an emotion or feeling that initiates and directs action towards an end" (pp. 131-132, Zagzebski, 1996). We can model the "instrinsic motivation" requirement along Zagzebski's view. Then one could see an intrinsically motivated person as someone with a persistent tendency to be moved by motive $\mathrm{x}$. Motive $\mathrm{x}$ can be an emotion like inspiration or love of the creative medium, whether it is the language of a strategy document or paint on a canvas.

To summarize, the virtue of creativity requires a teleological component of producing new and valuable output, a procedural component, having a degree of mastery and a motivational component, intrinsic motivation. Yet in some artists, musicians or scientists, not all of these components are present. For instance, someone may be able to create novel and worthwhile artifacts through mastery, but be solely extrinsically motivated. In these cases, Kieran states, we can attribute creativity to the person, but it is not creativity as a full virtue of character (Kieran, 2014). To possess the virtue, an agent must fulfill all requirements of this definition. Various virtue ethicists have distinguished virtue from capacity or skill in this way. A virtue is much more demanding and much more valuable, although skills and capacities also have value or are desirable.

\section{When Does an Innovator Possess the Virtue of Creativity?}

The previous section details how a substantive account of each component of the virtue of creativity is context-dependent. The virtue of creativity looks different in a painter than it does in a hedge-fund owner or football player. Therefore, for the context of product and service innovation, the virtue of creativity will have its own qualities that align with the values and the purpose of the context.

When, then, does a product and service innovator possess the virtue of creativity? To answer this question, we apply the framework based on Kieran's definition to the context of innovation, to develop an innovation-specific definition of creativity as a virtue. We will treat the different components of Kieran's definition separately for the sake of clarity.

${ }^{4}$ For a discussion of authorship in art, see Irvin (2005). 


\section{Teleological}

The teleological component is the ability to create novel and worthwhile ideas and artifacts. What is "worthwhile" is context-specific. Therefore we must reflect on the purpose of innovation and the values inherent to it to determine what the teleological component of creativity in innovation is. We begin by using some philosophical work on the purpose of innovation, supplementing and nuancing it with work from other fields.

Van den Hoven, Lokhorst and van de Poel have argued that the purpose of innovation should be to create the ability to fulfill an obligation which could previously not be fulfilled. The authors discuss problems of moral overload, which means that there are two duties which can not both be fulfilled practically (Van den Hoven, Lokhorst, \& Van de Poel, 2012). For instance, a parent can face a problem of moral overload if a sleeping baby prevents him from attending a new neighbor's housewarming. On the one hand a parent has a duty to respond if their child cries, on the other, he may have a friendship or community-related duty to attend the housewarming. A solution to this problem of moral overload is the baby phone. The baby phone allows the parent to fulfill both obligations, one of which could not be fulfilled without the baby phone (Van den Hoven et al., 2012). Innovations that make it possible for us to fulfill more moral duties than we otherwise could are definitely worthwhile.

However, requiring that an innovation solves a problem of moral overload seems overly restrictive. Many innovations are clearly creative and ingenious, even if they do not solve a moral problem. ${ }^{5}$ Definitions of innovation found in innovation studies tend to be more inclusive in terms of purpose, but more restrictive in terms of context. Here is one such definition: "Innovation is the multi-stage process whereby organizations transform ideas into new/improved products, service or processes, in order to advance, compete and differentiate themselves successfully in their marketplace (Baregheh, Rowley, \& Sambrook, 2009)" This definition suggests that the purpose of innovation is to allow organizations to differentiate themselves in the marketplace. This can certainly be a purpose of innovation, much like solving moral problems, but it is not a defining feature of all successful innovation.

What seems to be a defining feature of successful innovation is usefulness. Usefulness seems to be an underlying assumption in both characterizations of innovation. Usefulness we take to mean that it allows an action which was previously not possible or not possible in a certain situation. The baby phone is a good innovation because it makes it possible for a parent to attend a party next door

\footnotetext{
5 This point was raised by two anonymous reviewers.
}

and be responsive towards his baby at the same time. The innovation is therefore useful. In order to differentiate an organization in the marketplace, an innovation must also be useful. Some may argue that to be novel and worthwhile an innovative object does not need to be useful. An object can also be a novel way to use a material or an idea never executed before. However, we would maintain that such a useless but original artifact can be novel and worthwhile, for its aesthetic value, inasmuch as it is an artistic object. A useless object which was meant to be a useful innovation is, however, a failure. An innovator who produces aesthetically novel and worthwhile objects, which solve no problems, lacks the mastery to be virtuously creative. The ideas or artifacts she or he produces also lack the worthwhileness to be creative as innovations. They may, of course, qualify as the result of artistic creativity, if they can be regarded as a work of art, and if she or he intended them that way.

If "worthwhile" in the context of innovation means "useful," then readers are bound to raise the question "useful for what?" If someone innovates a new and useful way of torturing people, should this count as worthwhile? ${ }^{6}$ Many philosophers have discussed whether a virtue can be misguided and aim at the wrong goals. A Nazi's actions can be made much worse if the Nazi is courageous. Does a courageous Nazi really possess the virtue of courage? Our position on this is that a virtue is still a virtue, with all the inherent value of a virtue, even if it is bad-making. Creativity in a torturer may make their actions much worse, just like courage in a Nazi can. However, the badness in both cases is not a result of the creativity or courage, but because of other vices of character, like cruelty, insensitivity or close-mindedness. Had the Nazi or the torturer not possessed these vices, then their character would have been good in virtue of their creativity or courage. We are aware that this is a contested claim and some virtue theorists would disagree with us. However, this discussion goes outside the scope of this paper. $^{7}$

\section{Procedural}

In addition to the creation of novel and useful innovations, to be creative, an innovator should possess enough mastery to know what she or he is doing in the relevant discipline of innovation. What level of competence counts as mastery should be evaluated according to appropriateness per case. An innovator doesn't need to know the precise details of how self-confidence works in people, down to the neurochemical

\footnotetext{
6 This point was raised by an anonymous reviewer.

7 For a discussion on the case of courage as a "bad-making" virtue, see pp. 15 Foot (1978) for an argument that courage is not always a virtue. See also pp. 92-93 of Zagzebski (1996) for an argument that a courageous Nazi in fact does possess the virtue of courage.
} 
level, in order to create an app which helps people develop self-confidence. Rather, the person should understand apps and how they are used, and have a sufficient understanding of self-confidence and the lack of it. However, in the case of a chemist creating new drugs for mood disorders, creativity should be accompanied by mastery which includes an understanding of mood at the neurochemical level.

Kieran discusses the role of "happy accidents" in the creative process of artists (Kieran, 2014). These accidental discoveries can also happen in product and service innovation. In this context they can also count as an exercise of creative mastery, as long as the agent is capable of recognizing the innovative potential of the happy accident and decides to act on this recognition. Safety glass was invented by a chemist who knocked over a flask that had contained nitrocellulose. The flask was still intact. The creation of the nitrocellulose coating inside the flask, and the dropping of the flask were not done intentionally to create safety glass. However, the chemist noticed the flask and saw its innovative potential, reverse engineered what had happened and eventually patented safety glass (Ewing, 1936). The chemist's mastery of chemistry was crucial in him recognizing the fallen flask as a source of discovery.

\section{Motivational}

Now we come to the final component of creativity, intrinsic motivation. In the context of product and service innovation, this involves being motivated by the values inherent to innovation. Which values, then, are inherent to product and service innovation?

What distinguishes the values inherent to art from the values inherent to product and service innovation is that good products and services must be useful. As stated previously, product and service innovation has the telos of making an action possible which was previously not possible, or alternatively creating useful products. Van den Hoven et al. outline one more specific telos of high-tech innovation, making it possible to fulfill two duties in a situation of moral overload (Van den Hoven et al., 2012). A more business-oriented telos of innovation is differentiating oneself in the marketplace (Baregheh et al., 2009). Making useful products or services, ones that solve moral problems, or ones that have features that make them sell well can all be relevant sources of value for the domain of product and service innovation. An intrinsically motivated product or service innovator may therefore be motivated by the thought of making a good or successful product. Steve Jobs, former CEO of Apple, famously had precisely this kind of motivation (Isaacson, 2013). Whereas someone who designs phones just because the salary is good, without being interested in the product itself, is likely not intrinsically motivated.
The values required for intrinsic motivation can be the values internal to the sub-discipline of innovation that the innovator is working with. An innovator may, for instance, be intrinsically motivated by the creation of more sustainable cars through a fascination with cars or through taking pleasure in the design of intricate machines. Since innovation is a broad label that covers many different types of activities, it follows that many different types of motivations can count as intrinsic to product and service innovation processes. Sand suggests that at the root of a driven innovator's character often lies "an appetite for change" (Sand, 2018). However, an appetite for change by itself is not sufficient to constitute intrinsic motivation. The appetite must also be connected to the values inherent to product and service innovation. A burning appetite for a change in how one is viewed by peers is not connected to these values. An innovator motivated by such an appetite is not intrinsically motivated. If an innovator has an appetite for change in the sense that one wants to see people do things which were previously impossible, that is connected to one's desire to create a product that allows this, then such a person is intrinsically motivated for product and service innovation. This appetite must also be strong and motivating enough to drive the person to reliably exercise their creativity.

If we add the above reflections to Kieran's definition of a virtuously creative person, we can formulate a description of a virtuously creative innovator:

Someone who has acquired a certain degree of mastery and knows what she or he is doing in coming up with novel and worthwhile ideas or artifacts. Worthwhile innovations are those that are useful, or solve some practical problem. In doing so, the virtuously creative innovator is motivated by the values internal to innovation. These values can be specific to the craft or subdomain of innovation, or values inherent to innovation itself. Having an appetite for change qualifies as being motivated by values inherent to innovation, if she or he chooses what she or he does for reasons that hook up with those values in the right kind of ways.

This definition applies to individual creative innovators. But this individualistic definition does not describe the kind of creativity that is exhibited in Pixar's movie production process. As we outlined earlier, collective forms of creativity are important in many innovation practices. In a collaborative context like innovation, a definition of creativity which only applies to individuals is at risk of becoming redundant. Having characterized what it means to have the virtue of creativity in innovation, let us turn to the following question: Can groups possess the virtue of creativity in innovation? 


\section{Can Collectives Possess the Virtue of Creativity in Innovation?}

It is not immediately obvious that the virtue of creativity in innovation can be a proper group virtue. Various arguments have been made for the existence of group virtues in general (Beggs, 2003; Fricker, 2010; Lahroodi, 2007; Sandin, 2007). These accounts have not treated very extensively the structure of specific virtues in collective form. The virtue of creativity as a collective virtue is yet unexplored by philosophers. Contemporary innovation, in the style of Google and Pixar, presents an excellent test-case for collective creativity (Hill, 2014). In order to answer the question "Can collectives possess the virtue of creativity in innovation?" let us begin by investigating whether collectives can be agents that possess the teleological, procedural and motivational components of the virtue of creativity.

\section{Teleological: The Collective is Coming up with Novel and Worthwhile Ideas or Artifacts: Worthwhile Innovations Are Those That Are Useful or Relieve, or Contribute to Relieving, Problems of Moral Overload}

At first glance it seems unproblematic that collectives can fulfill the teleological component of the virtue of creativity. Companies that solve practical problems by innovating are examples of collectives coming up with novel and worthwhile artifacts. However, one can still question whether talking about collectives inventing things is just short-hand for talking about the individuals inventing things that contribute to the innovation in question. At the heart of this is the question: Can a collective be an agent?

While the exact nature of collective agency has been disputed for a long time in philosophical literature, many philosophers have argued that collective agency exists and can be meaningfully analyzed (Huebner, 2016; List \& Pettit, 2011; Searle, 1990). List and Pettit's influential account sets three conditions for collective agency, which they call "group agency". The authors argue that a random collective of people, such as a collection of people inside a supermarket at a given moment, do not, however, constitute agents. Collective agency only emerges when a collective has representational states, motivational states and the capacity to intervene in the environment, hence the term "group agency" rather than collective agency. These components of group agency are aggregations of representational and motivational states, and actions of individual group members. The group agency, however, supervenes the individual contributions of which it is aggregated. The fact that the actions of the group are ultimately caused by individuals is not seen as problematic for group agency (List \& Pettit, 2011).
Settling the debate about group agency, and various dependent concept, like group responsibility, is outside the scope of this article. We acknowledge that to those who find group agency and group responsibility unconvincing, the conception of collective virtue, and also collective creativity, will be unconvincing. It may be possible to argue that group virtues and a virtue of group creativity are possible without the need for group agency or group responsibility. However, that too, is outside our scope. Therefore, we will make the assumption that groups can take actions which supervene upon the actions of individuals in the group, and for which the group, as a whole, is responsible. We will also assume with List and Pettit that group responsibility can in some cases supervene upon the moral responsibility of individual group members, so that the group, rather than the members, are responsible for something. The question we attempt to settle here is not: "Can groups be agents and can they be held responsible as groups?" but rather "Given that groups can take actions that supervene upon individual actions, and reasonably be responsible for actions, in a way that supervenes the responsibility of individuals, can creativity as a virtue be the kind of thing that a group practices on this supervening level?"

If we accept the abovementioned assumptions and continue this line of questioning, then we may ask: "can a group come up with novel and worthwhile ideas or artifacts?" Intuitively, it seems that a group can do such things. The development of complex ideas or artifacts often requires the collaboration of many people. In fact, policy-makers have recognized that finding solutions to many of the practical problems that society struggles with today require collaboration between different disciplines and sectors of society (European Commission, 2020; Mauser et al., 2013). The idea that addressing societal challenges requires a diversity of parties already implies that collaboration is needed for innovation to be worthwhile. If this claim is true, then groups can have capabilities superior to individuals with regard to the teleological component. Groups are in some cases better capable of creating novel and worthwhile innovations. If groups are in some cases capable of things that individual members are not capable of, as in the case of innovation, there is good reason to accept that groups can come up with novel and worthwhile ideas or artifacts. The teleological component of the virtue of creativity can be fulfilled.

Let us, therefore, turn to the procedural component.

\section{Procedural: The Group Has Acquired a Certain Degree of Mastery and Knows What It Is Doing}

Possessing the procedural component would mean that the group has mastery over the craft at hand. The idea that groups can master something is relatively common in 
colloquial speech. People often talk about a football team or a band as being excellent at playing football or music. But can we truly speak of a group mastering something?

Let us begin with whether groups can acquire mastery. If a group agent, such as an institution, exists over a longer period of time, then it can also develop capacities. The ability to collaborate efficiently is often, if not always, an acquired capacity of groups. Groups often need time to function optimally. This is a fairly familiar experience from most people's working life, or personal relationships. While innovating requires various capacities, group work, or innovating with others is in itself a capacity that is acquired through experience.

And does this acquired mastery resemble individual creative mastery? We believe that both intentional creation and judgements regarding happy accidents can be made by collectives of people. A group like a company or a research team can have a shared intention. List and Pettit would call such a group a "jointly intentional group agent" (List \& Pettit, 2011). The group can carry out its intentions in different ways. For instance, a software company can have the intention to make an intuitively designed app with a certain purpose. The company can employ a designer, who is able to carry out the intention of the intuitive design. The writing of the app is carried out by those with skills in development and a manager can ensure that the app fulfills its purpose effectively. The group's joint intention is brought about by mastery distributed over different people.

One could argue that such instances of group mastery can be reduced to individual mastery. Development processes for new products and services are complex and require many people. But does the "group mastery" not simply boil down to individuals possessing mastery over their own contributions, making "group mastery" just short-hand for collection of individual mastery? We would argue that in some cases, this is indeed the case. However, there are special types of mastery which truly supervene upon the mastery of individuals.

The kinds of truly supervenient mastery are described well by Palermos and Tollefsen's conception of "group know-how." The authors argue that the difference between truly supervenient "group know-how" and a mere collection of individual capabilities is the interactions between those activities. "When individual members coordinate on the basis of reciprocal interactions, they adapt mutually to each other by restricting their actions in such a way so as to reliably - that is, regularly - achieve ends that they would only luckily, if ever, bring about were they to act on their own" (Palermos \& Tollefsen, 2018).

Collective creativity of the sort that Pixar and Google show seems to involve exactly this kind of know-how. The routine of dialogues, discussions and conflicts that Pixar employees are encouraged to engage in requires coordination and each individual action within the routine incites a response from others. The routine of lateral communication and sharing that Google employees engage is also coordinated to be such that it yields results which individuals could not achieve.

One group member can cause a "happy accident" and it may take a discussion between two other group members to recognize it as a possible good idea, while yet another pair is able to reverse engineer the happy accident, in response to the recognition that it may be a good idea. In group agents, control and mastery can be distributed over different members and united by the joint intention of the group and the joint nature of the capabilities of the group. It seems then, that the conception of group mastery describes well what goes on in many innovation practices.

\section{Motivational: The Group Is Motivated by the Values Internal to Innovation. These Values Can Be Specific to the Craft or Sub-domain of Innovation, or Values Inherent to Innovation Itself. Having an Appetite for Change Qualifies as Being Motivated by Values Inherent to Innovation. It Chooses What It Does for Reasons That Hook up with Those Values in the Right Kind of Ways}

In contrast to the requirement of the teleological component, intrinsic motivation, seems, at first sight, to be the most difficult when applied to groups. Even if we accept that a group can possess "group know-how" or collective mastery, can it possess something like a supervenient group motivation? And if so, is it possible for a group be intrinsically motivated to do something?

The focus here is the question "Is it possible for a group to possess a supervenient group motivation?" We will propose an account of how this may be possible, using Miranda Fricker's work regarding collective motivations. Fricker constructs an account of collective motivations to argue for the existence of institutional virtues. ${ }^{8}$ We will use insights from her work to argue for the possibility of a group analogue of intrinsic motivation. We do not wish to adopt her exact view of institutional virtue but merely to adopt concepts and argumentation she uses. Showing that groups can possess this analogue of intrinsic motivation will provide evidence for the motivational component needed for the existence of creativity as a collective virtue.

Fricker introduces the concept of a practical identity which members of an institution share and which can prompt certain virtuous or vicious actions. She introduces the concept in order to argue for the possibility of institutions possessing virtues, even in cases where not all members of the

\footnotetext{
${ }^{8}$ For a critical discussion of Fricker's thesis, see Cordell (2017).
} 
institution are virtuous individually. She discusses the virtue of fairmindedness in the case of a jury. We will use her conception of a practical identity to show that it can serve as a basis for group motivation. We shall first explain Fricker's use of the conception.

With regard to the possibility of institutions having virtue, Fricker outlines three views: the summativist view, the collectivist view and an in-between view, which she argues for. The summativist view sees collective virtues as a summation of all the individual virtues within a group. Within this view, an institution being virtuous would mean that all members are individually virtuous. Fricker rejects the summativist view for the reason that it is too demanding. We should still be able to call a jury fair-minded if it behaves fair-mindedly, even if there is one un-fair-minded person in the jury (Fricker, 2010).

The collectivist view states that if a group functions reliably in such a way that it manifests the virtue, then it possesses the virtue. According to this view a jury which is diversely biased, and comes to a fair-minded conclusion due to the cancelling out of biases, can be called fair-minded. Fricker also does not agree with the collectivist view, because she does not see a possibility of there being a virtuous motivation present in such a group. While the summativist view is too demanding, the collectivist view, according to Fricker is too lenient (Fricker, 2010). Thus, she argues for an in-between view: a form of summativism with the possibility of collective motivations.

This in-between view is that collective virtues can be the summation of individual virtues and the practical commitments that influence virtuous group behaviour. Fricker defends this view. According to Fricker, we cannot speak about a jury being virtuously fair-minded if the only reason it acts fairmindedly is that members' biases cancel each other out. However, in a jury where a few people are fair-minded, and others, though not fair-minded, have a willingness to go along with the fair-minded ones, out of a sentiment of professional loyalty, for instance, we can meaningfully speak of an institutional virtue. The institutional virtue consists of the virtues of some individuals and the commitments of the others to go along with their virtuous decisions (Fricker, 2010). Fricker's view is that if enough people in the group have a virtuous motivation or are willing to "go along with" a virtuous motivation, or take a virtuous practical identity, then a group virtue can be ascribed to the collective.
Practical identity refers to the identity that a person adopts as a part of their commitment to membership in a group or institution. The distinction one makes between speaking personally and speaking as a member of a group, or from a particular role, is the distinction between personal and practical identity. Practical identities can be significantly different from personal identity, also in morally relevant ways. Lahroodi discusses the following example. A church committee consists of members that are individually open-minded about gay rights. However, when they get together as the church committee, they become closeminded. They might do this because they feel it is their duty to take the close-minded view of the church within their practical identity as church committee members (Lahroodi, 2007). Similarly, group members may take on a practical identity which is morally superior to their personal attitudes. In such cases, Fricker argues, the practical identity can provide a substitute for virtuous motivations of individuals. If a practical identity containing a virtuous motivation is taken on by members, then it is fair to attribute a virtue to such a group or institution (Fricker, 2010).

The question we are interested in is: Can intrinsic motivation be a practical identity and hence function as the motivational component of the virtue of creativity in groups? We suggest that it can because intrinsic motivation can be a part of a practical identity. People working at Pixar, who might not themselves be virtuously motivated, can "go along with" the intrinsic motivation of others in various ways. One may help uphold a culture of enhancing intrinsic motivation. One may recognize the intrinsic motivation of others and put measures in place to keep it up, even while being extrinsically motivated oneself. Google is notorious for fostering a culture that is conducive to innovation by maintaining an open and reflexive culture and rewarding "Googley" behavior (Steiber \& Alänge, 2013). One may also "go along with" a creative idea for the sake of exploration even though one does not necessarily delight in that activity, but knows that it is important to explore creatively. An employee of Google may go along with certain decisions, because doing so would be "Googley." If a group takes on such a practical identity, then, just as in the case of a fair-minded jury, a creative company can include people with no virtuous motivation but a practical identity which favors creativity and creative activity for its own sake. This way, a group can have an intrinsic motivation without any individual even having one. The nature of this practical identity is inherently social. Again, 
possessing the virtue requires besides motivation also the other two components, procedural and teleological. If a group intrinsic motivation, like described here, is combined with supervenient socially construed and coordinated mastery over the process of coming up with novel and worthwhile ideas, then the group possesses a group virtue of creativity which cannot be reduced to traits of its individuals.

\section{Components of Creativity as a Virtue}

\begin{tabular}{|c|c|c|c|}
\hline & $\begin{array}{l}\text { Teleological } \\
\text { component }\end{array}$ & $\begin{array}{l}\text { Procedural } \\
\text { component }\end{array}$ & $\begin{array}{l}\text { Motivational } \\
\text { component }\end{array}$ \\
\hline $\begin{array}{l}\text { A creative per- } \\
\text { son (Based } \\
\text { on Kieran, } \\
2018 \text { ) }\end{array}$ & $\begin{array}{l}\text { Comes up with } \\
\text { novel and } \\
\text { worthwhile } \\
\text { artifacts }\end{array}$ & $\begin{array}{l}\text { Has acquired } \\
\text { a certain } \\
\text { degree of } \\
\text { mastery } \\
\text { knows what } \\
\text { she or he } \\
\text { is doing in } \\
\text { coming up } \\
\text { with novel } \\
\text { and worth- } \\
\text { while ideas } \\
\text { or artefacts }\end{array}$ & $\begin{array}{l}\text { In doing so, she } \\
\text { or he is moti- } \\
\text { vated by the } \\
\text { values internal } \\
\text { to the relevant } \\
\text { domain and } \\
\text { chooses what } \\
\text { she or he does } \\
\text { for reasons that } \\
\text { hook up with } \\
\text { those values in } \\
\text { the right kind } \\
\text { of ways }\end{array}$ \\
\hline $\begin{array}{l}\text { A creative } \\
\text { individual } \\
\text { innovator }\end{array}$ & $\begin{array}{l}\text { Coming up } \\
\text { with novel } \\
\text { ideas or } \\
\text { artifacts that } \\
\text { are useful or } \\
\text { relieve, or } \\
\text { contribute } \\
\text { to relieving, } \\
\text { problems } \\
\text { of moral } \\
\text { overload }\end{array}$ & $\begin{array}{l}\text { Has acquired } \\
\text { a certain } \\
\text { degree of } \\
\text { mastery in } \\
\text { innovation } \\
\text { or a relevant } \\
\text { sub-field of } \\
\text { innovation, } \\
\text { and hence } \\
\text { knows what } \\
\text { she or he is } \\
\text { doing }\end{array}$ & $\begin{array}{l}\text { Is motivated } \\
\text { by the values } \\
\text { internal to } \\
\text { innovation. } \\
\text { These values } \\
\text { can be specific } \\
\text { to the craft or } \\
\text { sub-domain of } \\
\text { innovation, or } \\
\text { values inherent } \\
\text { to innovation } \\
\text { itself }\end{array}$ \\
\hline $\begin{array}{l}\text { A creative } \\
\text { innovation } \\
\text { collective }\end{array}$ & $\begin{array}{l}\text { Engages in } \\
\text { collective } \\
\text { ideation } \\
\text { towards ideas } \\
\text { or artifacts } \\
\text { that are use- } \\
\text { ful or relieve, } \\
\text { or contribute } \\
\text { to relieving, } \\
\text { problems } \\
\text { of moral } \\
\text { overload }\end{array}$ & $\begin{array}{l}\text { Has acquired } \\
\text { mastery in } \\
\text { harnessing } \\
\text { different } \\
\text { skills dis- } \\
\text { tributed over } \\
\text { members and } \\
\text { a capacity to } \\
\text { collaborate }\end{array}$ & $\begin{array}{l}\text { Is driven by } \\
\text { aggregated } \\
\text { intrinsic } \\
\text { motivation of } \\
\text { members for } \\
\text { innovation } \\
\text { or various } \\
\text { sub-domains } \\
\text { of innovation } \\
\text { and/or a shared } \\
\text { practical } \\
\text { identity which } \\
\text { upholds and } \\
\text { stimulates } \\
\text { intrinsic moti- } \\
\text { vation }\end{array}$ \\
\hline
\end{tabular}

\section{Implications of Creativity as a Collective Virtue}

Collective creativity is a much-discussed topic in organizational psychology, design and management literature. Collective creativity is something which innovation groups can and should develop and foster (Hill, 2014). Considering the amount of attention in other fields that deal with innovation, surprisingly little philosophical work has been devoted to the moral value of collective creativity. In this article, we have analyzed the possibility of regarding collective creativity as a collective virtue.

Our approach has been to dissect Kieran's definition of creativity as an individual virtue into three components, teleological, procedural and motivational, and see whether each can be applied to a collective. One may contest this approach and argue that collective creativity should not be investigated with an individualistic definition as a starting point. We do not claim that the originally individualistic definition of creativity is the only correct one and that more research into virtuous group creativity would not yield a better definition. Showing that Kieran's definition can be applied to groups merely demonstrates that it makes sense, philosophically, to attribute a virtue like creativity to groups. This can likely be done with other virtues too.

If one accepts that group creativity is a virtue, then one accepts that it is prima facie valuable. This has substantive consequences for various ethical decisions in innovation. Firstly, it means that organizations should facilitate collective creativity and that it is worth pursuing it its own right. Collective creativity may come into conflict with other values. For instance, facilitating an inclusive process can take more time than developing a much-needed product quickly. If collective creativity is recognized as a virtue, and thus inherently good, then abstaining from bringing it about should be seen as a sacrifice. The nature of the sacrifice would be giving up developing something that is inherently good. We intend our account of group creativity as a virtue to be an addition to existing literature on the virtues in innovation, the existing literature being largely individualistic (Brenkert, 2009; Sand, 2018; Steen, 2013). Accounting for the good of creativity in innovation as an individual virtue only, and not as we suggest, as a collective virtue, also has some limitations.

Secondly, a more practical consequence of recognizing collective creativity as a virtue is that it may provide new reasons for adopting more collective types of intellectual property frameworks, or crediting practices more broadly. If a group can be credited with the virtue of creativity, then perhaps this means that collectively created products should be credited to collectives, rather than compartmentalizing and crediting individual contributions. 
There is also a normative argument to be made for why collective creativity should be recognized as a virtue. Only recognizing individual creativity incentivizes a perverse obsession with individual visionaries and creative geniuses. This, one could argue, can lead to a competitive atmosphere which discourages cooperation and collective or communityoriented thinking. In accepting that collective creativity is just as excellent and inherently valuable as individual creativity is likely to motivate the creation of more collaborative and less competitive environment for innovation to happen.

Of course we should not think that innovations used for torturing people are good if the process of innovating them was creative. However, we should also not ignore the fact that a huge part of the population is in some way involved in product or service innovation, and the meaningfulness of one's work is a big part of one's wellbeing. Innovation is not merely a means to an end, but a valuable human activity in itself. Even with the risk of justifying foolhardy innovators conduct, the value of innovating as an activity should be taken seriously.

Additionally, some organizational psychologists would argue that it is simply not true that innovation is always driven by creative geniuses (Hill, 2014). An individualist virtue approach to creativity is likely to emphasize the contribution of gifted individuals even in cases where the contribution of the group played an essential role. Additionally, there is often no single genius behind every good innovation. In fact, scholars like Hill would even argue there should not be (Hill, 2014). Co-creation and participatory innovation processes are often praised because they allow different parties contribute with their ideas and experience, not to realize the vision of one or two geniuses. The co-creation process taps into the collective genius of a diverse group (Sanders \& Stappers, 2008). Therefore, in many cases an individualistic account of creativity as a virtue in innovation is simply not an accurate description of what happens in an innovation practice. To be empirically accurate, a virtue approach to innovation should recognize collective creativity. We have shown that it is, at least whilst making some assumptions, possible.

Acknowledgements Thanking Shelly Tsui and Anna Melnyk for providing valuable feedback on the manuscript.

Funding This project is a part of H2020 Project SCALINGS. This project has received funding from the European Union's Horizon 2020 research and innovation programme under Grant Agreement No. 788359.

\section{Declarations}

Conflict of interest The authors declare that they have no conflict of interest.
Open Access This article is licensed under a Creative Commons Attribution 4.0 International License, which permits use, sharing, adaptation, distribution and reproduction in any medium or format, as long as you give appropriate credit to the original author(s) and the source, provide a link to the Creative Commons licence, and indicate if changes were made. The images or other third party material in this article are included in the article's Creative Commons licence, unless indicated otherwise in a credit line to the material. If material is not included in the article's Creative Commons licence and your intended use is not permitted by statutory regulation or exceeds the permitted use, you will need to obtain permission directly from the copyright holder. To view a copy of this licence, visit http://creativecommons.org/licenses/by/4.0/.

\section{References}

Anscombe, G. E. M. (1958). Modern moral philosophy. Philosophy, 33(124), 1-19. https://doi.org/10.1017/S0031819100037943

Aristotle. (2015). In C. H. Poortman \& Bartel (Trans.), Ethica Nichomachea (4th ed.). Uitgeverij DAMON.

Baregheh, A., Rowley, J., \& Sambrook, S. (2009). Towards a multidisciplinary definition of innovation. Management Decision, 47(8), 1323-1339. https://doi.org/10.1108/00251740910984578

Bassett-Jones, N. (2005). The paradox of diversity management, creativity and innovation. Creativity and Innovation Management, 14(2), 169-175. https://doi.org/10.1111/j.1467-8691.00337.x

Beggs, D. (2003). The idea of group moral virtue. Journal of Social Philosophy, 34(3), 457-474. https://doi.org/10.1111/1467-9833. 00194

Belbin, R. M. (2012). Team roles at work (2nd ed., pp. 1-153). London: Taylor; Francis. https://doi.org/10.4324/9780080963242

Boden, M. A. (2003). The creative mind: Myths and mechanisms. Routledge.

Brenkert, G. G. (2009). Innovation, rule breaking and the ethics of entrepreneurship. Journal of Business Venturing, 24(5), 448464. https://doi.org/10.1016/j.jbusvent.2008.04.004

Carter, J. A. (2017). Virtuous insightfulness. Episteme, 14(4), 539 554. https://doi.org/10.1017/epi.2016.37

Catmull, E. (2008). How Pixar Fosters Collective Creativity. Harvard Business Review. https://hbr.org/2008/09/how-pixar-foste rs-collective-creativity.

Cordell, S. (2017). Group virtues: No great leap forward with collectivism. Res Publica, 23(1), 43-59. https://doi.org/10.1007/ s11158-015-9317-7

Driver, J. (1989). The virtues of ignorance. The Journal of Philosophy, 86(7), 373. https://doi.org/10.2307/2027146

European Commission. (2020). Open and Participative Innovation: Digital Single Market. https://ec.europa.eu/digital-single-market/en/open-and-participative-innovation. Accessed 9 Jan 2020.

Ewing, A. M. (1936). Turning accidents into profit through careful observation. Journal of Chemical Education. 530-532.

Foot, P. (1978). Virtues and vices and other essays in moral philosophy. University of California Press.

Fricker, M. (2010). 10. Can there be institutional virtues? In T. S. Gendler \& J. Hawthorne (Eds.), Oxford studies in epistemology (3rd ed., pp. 235-252). Oxford University Press.

Hill, L. A. (2014). Collective genius: The art and practice of leading innovation. Harvard Business Review Press.

Huebner, B. (2016). The group mind: In commonsense psychology. In J. Sytsma \& W. Buckwalter (Eds.), Blackwell companion to experimental philosophy (pp. 292-305). Wiley. 
Irvin, S. (2005). Appropriation and authorship in contemporary art. The British Journal of Aesthetics, 45(2), 123-137. https://doi.org/ 10.1093/aesthj/ayi015

Isaacson, W. (2013). Steve Jobs. Little Brown Book Group.

Kieran, M. (2014). Creativity as a virtue of character. In The philosophy of creativity (pp. 125-144). Oxford University Press.

Kieran, M. (2018). Creativity as an epistemic virtue. In H. Battaly (Ed.), Routledge handbook of virtue epistemology (pp. 167-177). Routledge.

Lahroodi, R. (2007). Collective epistemic virtues. Social Epistemology, 21(3), 281-297. https://doi.org/10.1080/02691720701674122

List, C., \& Pettit, P. (2011). Group agency: The possibility, design, and status of corporate agents. Oxford University Press.

Macdonald, J. E., \& Beck-Dudley, C. L. (1994). Are deontology and teleology mutually exclusive? Journal of Business Ethics, 13(8), 615-623. https://doi.org/10.1007/BF00871809

MacIntyre, A. (1986). After virtue (2nd ed.). University of Notre Dame Press.

Mauser, W., Klepper, G., Rice, M., Schmalzbauer, B. S., Hackmann, H., Leemans, R., \& Moore, H. (2013). Transdisciplinary global change research: The co-creation of knowledge for sustainability. Elsevier. https://doi.org/10.1016/j.cosust.2013.07.001

Mill, J. S. (1869). On liberty (4th ed.). Longman Roberts \& Green Co.

Palermos, S. O., \& Tollefsen, D. P. (2018). Group know-how (Vol. 1). Oxford University Press.

Paulus, P. (2003). Group creativity innovation through collaboration. Oxford University Press.

Sand, M. (2018). The virtues and vices of innovators. Philosophy of Management, 17(1), 79-95. https://doi.org/10.1007/ s40926-017-0055-0

Sanders, E.B.-N., \& Stappers, P. J. (2008). Co-creation and the new landscapes of design. CoDesign, 4(1), 5-18. https://doi.org/10. 1080/15710880701875068

Sanders, E.B.-N., \& Stappers, P. J. (2012). Convivial design toolbox: Generative research for the front end of design. BIS.
Sandin, P. (2007). Collective military virtues. Journal of Military Ethics, 6(4), 303-314. https://doi.org/10.1080/15027570701755505

Sawyer, R. K. (2012). Explaining creativity: The science of human innovation (pp. 586). Oxford University Press.

Searle, J. (1990). Collective intentions and actions. In P. R. C. J. Morgan \& M. Pollack (Eds.), Intentions in communication (pp. 401-415). MIT Press.

Steen, M. (2013). Virtues in participatory design: Cooperation, curiosity, creativity, empowerment and reflexivity. Science and Engineering Ethics, 19(3), 945-962. https://doi.org/10.1007/ s11948-012-9380-9

Steiber, A., \& Alänge, S. (2013). A corporate system for continuous innovation: The case of Google Inc. European Journal of Innovation Management, 16(2), 243-264. https://doi.org/10.1108/14601 061311324566

Van den Hoven, J., Lokhorst, G.-J., \& Van de Poel, I. (2012). Engineering and the problem of moral overload. Science and Engineering Ethics, 18(1), 143-155. https://doi.org/10.1007/ s11948-011-9277-z

Wikipedia. (2021). List of Pixar awards and nominations (feature films). https://en.wikipedia.org/wiki/List_of_Pixar_awards_and nominations_(feature_films). Accessed 13 Jan 2021.

Zagzebski, L. T. (1996). Virtues of the mind: An inquiry into the nature of virtue and the ethical foundations of knowledge. Cambridge University Press.

Zagzebski, L. T. (2017). Exemplarist moral theory. Oxford University Press.

Publisher's Note Springer Nature remains neutral with regard to jurisdictional claims in published maps and institutional affiliations. 